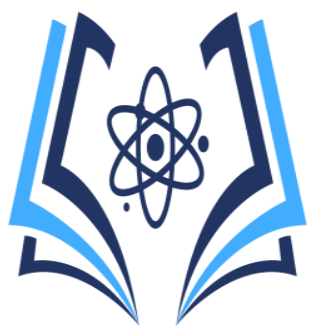

\title{
Virus del papiloma humano y factores de riesgos
}

\section{Human papillomavirus and risk factors}

\section{Virus del papiloma humano y factores de riesgos}

Evelin Eliana Palacios Toala Lic. en enfermería ${ }^{1}$

Gina Rosa Alonso Muñiz. Mg. Em ${ }^{2}$

Virginia Esmeralda Pincay Pin. Mg. Gs. ${ }^{3}$

María Elena Pincay Cañarte Mg. Gs. ${ }^{4}$

${ }^{1}$ Universidad Estatal del Sur de Manabí, evelineliana97@ hotmail.com

${ }^{2}$ Universidad Estatal del Sur de Manabí, gina.alonzo@unesum.edu.ec, https://orcid.org/0000-0003-0041-2956

${ }^{3}$ Universidad Estatal del Sur de Manabí, Virginia.pincay@unesum.edu.ec, https://orcid.org/0000-0001-87765433

${ }^{4}$ Universidad Estatal del Sur de Manabí, maria.pincay@unesum.edu.ec, https://orcid.org/0000-0003-41109275

Correo de contacto: gina.alonzo@unesum.edu.ec

Recibido: 29-04-2021

Aprobado: 18-06-2021

\section{Resumen}

El virus del papiloma humano afecta a cualquier persona sexualmente activa, esta enfermedad es tan común que las personas se pueden contagiar poco después de iniciar su vida sexual. Existen más de 150 tipos de virus, entre los cuales tenemos los de bajo riesgo VPH 6 y 11, y los de alto riesgo VPH 16 y 18. Es un virus que no tiene cura, pero se puede prevenir mediante la educación adecuada. El propósito del estudio fue determinar los factores de riesgos que influyen en el contagio del virus del papiloma humano. Se realizó un estudio descriptivo analítico no experimental, para la recolección de datos se utilizó instrumentos como la encuesta en el cual se la realizó a 37 mujeres, la encuesta permitió recoger información del conocimiento que tienen sobre el virus del papiloma humano, sus causas, síntomas, transmisión, factores de riesgos y medidas preventivas, además se realizó la entrevista al personal médico calificado. Los resultados mostraron que la mayoría de la población de estudio tiene conocimiento sobre el virus del papiloma humano, sin embargo, existe un porcentaje significativo que no lo tiene. A pesar de ser una población con pocos casos de VPH, es necesario educarlos para que tengan conocimiento de la enfermedad.
Palabras claves: Transmisión sexual, asintomático, Papanicolau, verrugas, cáncer cervicouterino.

\section{Abstract}

Human papillomavirus affects any sexually active person, this disease is so common that people can get infected shortly after starting their sex life. There are more than 150 types of viruses, including low-risk HPV 6 and 11, and high-risk HPV 16 and 18. It is a virus that has no cure, but can be prevented by proper education.

The purpose of the study was to determine the risk factors that influence the spread of human papillomavirus. A descriptive non-experimental analytical study was conducted, for the collection of data instruments were used such as the survey in which 37 women were conducted, the survey allowed to collect information about the knowledge they have about the human papillomavirus, its causes, symptoms, transmission, risk factors and preventive measures. In addition, the interview was conducted to qualified medical personnel. The results showed that the majority of the study population has knowledge about human papillomavirus, however, there is a significant percentage that does not.

Despite being a population with few HPV cases, it is necessary to educate them to be aware of the disease. 
Keywords: Sexual transmission, asymptomatic, pap smear, warts, cervical cancer

\section{Introducción}

Uno de los grandes problemas de salud pública a nivel mundial son las infecciones de transmisión sexual, que al no ser descubiertas a tiempo pueden ocasionar múltiples enfermedades incluso la muerte (1).

El virus del papiloma humano (VPH) es una enfermedad infecciosa de transmisión sexual común. $\mathrm{Su}$ causa es un virus de ADN (ácido desoxirribonucleico) no cultivable. Pertenece a la familia de los papilomas víridos y generalmente se llaman condiloma acuminado, verrugas genitales o cresta de gallo. El VPH se transmite por contacto sexual, en la mayoría de los casos no causa síntomas, pero las mujeres pueden experimentar picazón leve, dolor durante el coito o flujo vaginal. Este virus puede permanecer en el organismo durante mucho tiempo sin manifestarse y actúa en determinadas condiciones como la inmunosupresión fisiológica durante el embarazo y en condiciones patógenas como el VIH (2).

El mayor índice de contagios por VPH está asociada al inicio temprano de las relaciones sexuales en este grupo tenemos a los adolescentes y adultos jóvenes y aquellos con mayor número de parejas sexuales (3).

La Organización Mundial de la Salud (OMS) estima que el $80 \%$ de la población sexualmente activa en todo el mundo se infectará al menos una vez en su vida. De igual manera, cada año se reportan 500.000 nuevos casos de cáncer de cuello uterino, lo que resulta en 260.000 muertes por esta enfermedad (4).

Por otro lado, los informes de prevalencia del VPH varían según países, regiones y poblaciones. Se encuentra con mayor frecuencia en mujeres menores de 25 años en el mundo. La región con mayor prevalencia es Oceanía; sin embargo, en África este fenómeno es más común entre las mujeres mayores de 45 años (5) .

Según la Asociación Estadounidense contra el Cáncer, en la mayoría de los casos, el sistema inmunológico del organismo humano puede eliminar las infecciones por sí solo, pero a veces la infección no desaparece. Cuando la infección se vuelve crónica o a largo plazo, especialmente cuando es causada por determinantes del tipo de VPH considerados de alto riesgo, puede conducir al desarrollo de ciertos tipos de cáncer con el tiempo. Algunos estudios realizados en América del Sur, además del VPH 16 y el VPH 18, el VPH 58 es otro genotipo de alto riesgo. Este último tipo se encontró en el centro y norte de Brasil, Argentina, Colombia y Ecuador (6).

En 2009, la OMS informó que la incidencia del VPH en la frontera norte de Ecuador era alta, lo que provocaba cáncer de cuello uterino. En 2012, 664 mujeres murieron por la enfermedad y se estima que

\section{Vol. 4, Nro. 1, Publicado 2021-06-30}

aproximadamente dos mil mujeres tienen nuevos casos (7).

En la actualidad, existen "más de 100 tipos de VPH"(OMS,2015), algunos constituyen los serotipos que producen células cancerosas en el cuerpo y causan cáncer de cuello uterino. En Ecuador, la proporción de mujeres que padecen cáncer de cuello uterino relacionado con VPH es impactante porque se ha convertido en la segunda causa de muerte y el tercero en incidencia. Según la publicación de Solca en la epidemiología del cáncer en Quito, luego de 25 años de investigación, diversos indicadores muestran que esta situación continúa disminuyendo con el tiempo, pero aún es un número elevado para que la sociedad tome conciencia de las consecuencias de esta enfermedad (8).

Se estima que alrededor de 17 mujeres en Ecuador mueren de cáncer de cuello uterino cada semana, hay alrededor de 1.200 nuevos casos de VPH cada año y 300 muertes relacionadas con el virus. Esto puede sonar desafortunado, porque si se detecta temprano, esta es una enfermedad que se puede controlar. En cuanto a la incidencia de cáncer de cuello uterino en el mundo, en comparación con otros países, Ecuador se ubica en el lugar 12 y 14. La ciudad de Quito ocupa el primer lugar y la provincia de Cuenca ocupa el segundo lugar (8).

El Ministerio de Salud Pública (MSP) en el año 2014 incorporó como estrategia de prevención del cáncer de cérvix, la vacuna contra el VPH, el cual contempla dos dosis con un intervalo de 6 meses a niñas de 9 años. Estas se aplican de forma gratuita en todos los establecimientos de salud del MSP (9).

Según el informe estadístico de Solca Manabí, en el 2015 se reportaron 174 pacientes con virus de papiloma humano, y en el 2016 y 2017, 598 casos de cáncer de cuello uterino por virus del papiloma humano a nivel de Manabí (10).

El presente trabajo se lo realizo en el Centro de Salud Colorado, porque el problema radica en que hay una población joven sexualmente activa en riesgo, que han padecido infecciones de transmisión sexual, no utilizan métodos de barrera, han comenzado su vida sexual desde muy jóvenes y no llevan un buen control médico, lo que se determina son factores para poder desarrollar la enfermedad en un futuro.

El objetivo general es determinar los factores de riesgo que influyen en el contagio del virus de papiloma humano. Los objetivos específicos orientados a: identificar el nivel de conocimiento de los usuarios del Centro de Salud Colorado sobre el virus de papiloma humano, conocer las medidas preventivas del virus de papiloma humano, educar a los usuarios del Centro de Salud Colorado sobre los factores de riesgos que influyen en el contagio del virus de papiloma humano. 
La educación para la salud es un tema importante para que los profesionales de la salud promuevan la promoción y el mantenimiento de la buena salud. De ahí, que es importante discutir estas enfermedades que están directamente relacionadas con la sexualidad, la vida reproductiva de hombres y mujeres y por ende con la calidad de vida de las personas.

\section{Materiales y métodos}

El periodo de investigación fue de enero a marzo de 2021 en el Centro de Salud Colorado, ubicado en la parroquia colorado del Cantón Montecristi. Se realizo un estudio descriptivo analítico no experimental, ya que intenta acercarse al conocimiento, mediante las variables virus del papiloma humano (independiente) y factores de riesgos (dependiente). El método bibliográfico nos permitió recolectar información, analizarlas e interpretarlas con el objetivo de obtener datos científicos de diferentes autores. Además, se aplicó el método analítico y deductivo para la recolección de datos los cuales fueron encuestas dirigida a una parte de la población y entrevista realizada a un profesional de la salud.

La población total de la muestra en estudio estuvo constituida por 37 mujeres de la parroquia colorado. Como criterios de inclusión se consideró a usuarios de 15 a 50 años, con antecedentes de infección de transmisión sexual que fueron atendidos en el Centro de Salud Colorado y como criterio de exclusión a pacientes que fueron diagnosticados con otras patologías.
Vol. 4, Nro. 1, Publicado 2021-06-30

Realizada la recolección de datos para la investigación se realizó el respectivo análisis y conclusiones

\section{Resultados:}

La mayoría de la población en estudio tienen entre 2540 años en el estudio observamos que el 94,6\% tienen conocimiento sobre el virus del papiloma humano, sus causas, síntomas en comparación con un estudio realizado en Esmeraldas que sus encuestados tienen un conocimiento deficiente.

La muestra nos indica que la población conoce en qué consiste el Papanicolau sin embargo un elevado porcentaje $(48,6 \%)$ no lo realizan. Se evidencia en la tabla $\mathrm{N}^{\circ} 4$ que las encuestadas han tenido relaciones sexuales entre los 15 - 20 años, la mayoría solo han tenido una sola pareja, sin embargo, si hay porcentaje considerable que han tenido entre tres o más parejas sexuales, y el $89,2 \%$ han padecido infecciones de transmisión sexual, los resultados muestran que tienen conocimiento que el preservativo es una medida preventiva para la enfermedad, pero en la tabla $\mathrm{N}^{\circ} 5$ podemos evidenciar que la mayoría nunca lo utilizan estos resultados tienen similitud con el estudio realizado por Santiago y Suárez (11) quienes indicaron que el inicio precoz de las relaciones sexuales, la promiscuidad y la falta de protección suelen ser factores de riesgo asociados a la infección por VPH. Los resultados obtenidos se presentan a continuación con su respectivo análisis:

Tabla N ${ }^{\circ}$ : Indicadores sociodemográficos

\begin{tabular}{|l|l|l|l|l|}
\hline Orden & Alternativa & Frecuencia & Porcentaje & Total \\
\hline \multirow{4}{*}{ Edad } & $15-25$ años & 16 & $43,20 \%$ & \\
\cline { 2 - 4 } & $25-40$ años & 18 & $48,60 \%$ & \multirow{3}{*}{$100 \%$} \\
\cline { 2 - 4 } & Mayor de 40 años & 3 & $8,10 \%$ & \\
\hline \multirow{5}{*}{ Estado Civil } & Soltera & 22 & $59,50 \%$ & \\
\cline { 2 - 4 } & Casada & 2 & $5,40 \%$ & \\
\cline { 2 - 4 } & Divorciada & 3 & $8,10 \%$ & \\
\cline { 2 - 4 } & Unión Libre & 9 & $24,30 \%$ & \\
\cline { 2 - 4 } & Viuda & 1 & $2,70 \%$ & \\
\hline
\end{tabular}

Fuente: Mujeres de la Parroquia Colorado del cantón Montecristi

Análisis:

Los indicadores sociodemográficos juegan un papel importante a la hora de realizar una investigación. Se evidencia que de las 37 mujeres encuestadas en su mayoría tienen edades de $25-40$ años y el $43,2 \%$ en edades de 15 a 25 años; investigaciones realizadas en el 2017 por la revista cubana de obstetricia y Tabla N ${ }^{\circ}$ 2: Conocimiento del Virus del Papiloma Humano ginecología indica que esta es la edad de prevalencia para el pico de la infección por VPH (12). El estado civil de los encuestados representa el 59,5\% en la población soltera. Un estudio realizado en Ecuador en el Cantón Cañar mostro que la mayor probabilidad de infección se encontraba en mujeres solteras (13). 
Vol. 4, Nro. 1, Publicado 2021-06-30

\begin{tabular}{|c|c|c|c|c|}
\hline Orden & Alternativa & Frecuencia & Porcentaje & Total \\
\hline \multirow{2}{*}{$\begin{array}{l}\text { Conoce sobre el virus del } \\
\text { papiloma humano }\end{array}$} & $\mathrm{Si}$ & 35 & $94,6 \%$ & \multirow{2}{*}{$100 \%$} \\
\hline & No & 2 & $5,4 \%$ & \\
\hline \multirow{3}{*}{ Consecuencia del VPH } & Cáncer de cuello uterino & 34 & $91,9 \%$ & \multirow{3}{*}{$100 \%$} \\
\hline & Cáncer de mama & 2 & $5,4 \%$ & \\
\hline & Cáncer de ovarios & 1 & $2,7 \%$ & \\
\hline \multirow{2}{*}{$\begin{array}{l}\text { Síntomas del virus del papiloma } \\
\text { humano }\end{array}$} & $\mathrm{Si}$ & 23 & $62,2 \%$ & \multirow{2}{*}{$100 \%$} \\
\hline & No & 14 & $37,8 \%$ & \\
\hline \multirow{3}{*}{$\begin{array}{l}\text { Forma de transmisión más } \\
\text { común del virus del papiloma } \\
\text { humano }\end{array}$} & Contacto piel con piel & 2 & $5,4 \%$ & \multirow{3}{*}{$100 \%$} \\
\hline & $\begin{array}{l}\text { Durante las relaciones sexuales } \\
\text { vaginales o anales }\end{array}$ & 35 & $94,6 \%$ & \\
\hline & $\begin{array}{l}\text { Mediante la ropa o superficies } \\
\text { ambientales }\end{array}$ & 0 & $0 \%$ & \\
\hline
\end{tabular}

Fuente: Mujeres de la Parroquia Colorado del Cantón Montecristi

Análisis:

En la tabla $\mathrm{N}^{\circ} 2$ se puede apreciar que el 94,6\% de los encuestados si tienen conocimientos sobre el virus. La mayoría de estas mujeres manifiestan que el virus del papiloma humano es el causante de cáncer de cuello uterino. El 62,2\% tienen conocimientos sobre los síntomas del virus. Respecto a la información sobre la forma de transmisión, la mayoría respondió correctamente, ya que indicaron que es por medio de contagio sexual, solo el $5,4 \%$ respondieron erróneamente.

Tabla $N^{\circ}$ 3: Papanicolau

\begin{tabular}{|c|c|c|c|c|}
\hline Orden & Alternativa & Frecuencia & Porcentaje & Total \\
\hline \multirow{3}{*}{$\begin{array}{l}\text { Conocimiento } \\
\text { sobre el } \\
\text { Papanicolau }\end{array}$} & $\begin{array}{l}\text { Consiste en el raspado de cuello uterino con la } \\
\text { ayuda de un instrumento similar a un hisopo }\end{array}$ & 22 & $59,5 \%$ & \multirow{3}{*}{$100 \%$} \\
\hline & $\begin{array}{l}\text { Prueba serológica para identificar los } \\
\text { anticuerpos con el virus del VPH que circulan } \\
\text { en el organismo }\end{array}$ & 10 & $27,0 \%$ & \\
\hline & $\begin{array}{l}\text { Es un método de detección molecular más } \\
\text { específico para identificar el VPH }\end{array}$ & 5 & $13,5 \%$ & \\
\hline \multirow{4}{*}{$\begin{array}{l}\text { Frecuencia que } \\
\text { se ha realizado } \\
\text { un examen de } \\
\text { Papanicolau }\end{array}$} & Cada 6 meses & 0 & $0 \%$ & \multirow{4}{*}{$100 \%$} \\
\hline & Cada año & 14 & $37,8 \%$ & \\
\hline & Cada dos años & 5 & $13,5 \%$ & \\
\hline & Nunca & 18 & $48,6 \%$ & \\
\hline \multirow{3}{*}{$\begin{array}{l}\text { Quiénes deben } \\
\text { realizarse la } \\
\text { prueba del } \\
\text { Papanicolau }\end{array}$} & Las mujeres que inician su vida sexual & 29 & $78,4 \%$ & \multirow{3}{*}{$100 \%$} \\
\hline & Mujeres mayores de 18 años & 5 & $13,5 \%$ & \\
\hline & No sabe & 3 & $8,1 \%$ & \\
\hline
\end{tabular}

Fuente: Mujeres de la Parroquia Colorado del cantón Montecristi

Análisis:

En la tabla $\mathrm{N}^{\circ} 3$ se puede observar que el $59,5 \%$ de las encuestadas tienen conocimiento en qué consiste el Papanicolau. Según la profesional de salud en esta área indica que el Papanicolau está dentro de uno de los programas del Ministerio de Salud Pública, razón por la cual siempre se debe realizar la prueba a las mujeres sexualmente activas. Sin embargo, el 48,6\% de las mujeres nunca se han realizado el examen a pesar de que en los distintos establecimientos de salud lo realizan de manera gratuita, solo el $37,8 \%$ lo realizan cada año. La mayoría de las encuestadas consideran que deben realizarse la prueba de papanicolau aquellas mujeres que han iniciado su vida sexual. Un estudio realizado por Almendariz (14), explicaba que uno de los factores que afectan a las mujeres sexualmente activas para no realizarse una prueba de papanicolau es el miedo a los resultados, además de la incomodidad de la mujer de exponer sus partes íntimas. 
Tabla N 4. Factores de riesgos del VPH

\begin{tabular}{|c|c|c|c|c|}
\hline Orden & Alternativa & Frecuencia & Porcentaje & Total \\
\hline \multirow{5}{*}{$\begin{array}{l}\text { Inicio de su vida } \\
\text { sexual }\end{array}$} & $12-15$ años & 4 & $10,8 \%$ & \multirow{5}{*}{$100 \%$} \\
\hline & 15 - 20 años & 16 & $43,2 \%$ & \\
\hline & 20 - 30 años & 13 & $35,1 \%$ & \\
\hline & Más de 30 años & 0 & $0,0 \%$ & \\
\hline & Nunca & 4 & $10,8 \%$ & \\
\hline \multirow{4}{*}{$\begin{array}{l}\text { Número de parejas } \\
\text { sexuales }\end{array}$} & Cero & 3 & $8,1 \%$ & \multirow{4}{*}{$100 \%$} \\
\hline & Uno & 14 & $37,8 \%$ & \\
\hline & Dos & 8 & $21,6 \%$ & \\
\hline & Tres o más & 12 & $32,4 \%$ & \\
\hline \multirow{2}{*}{$\begin{array}{l}\text { Antecedentes de } \\
\text { ITS }\end{array}$} & $\mathrm{Si}$ & 33 & $89,2 \%$ & \multirow{2}{*}{$100 \%$} \\
\hline & No & 4 & $10,8 \%$ & \\
\hline \multirow{4}{*}{$\begin{array}{lr}\text { Factores } & \text { que } \\
\text { predisponen } & \text { al } \\
\text { contagio del VPH }\end{array}$} & Promiscuidad (varias parejas sexuales) & 20 & $54,1 \%$ & \multirow{4}{*}{$100 \%$} \\
\hline & Verrugas genitales & 12 & $32,4 \%$ & \\
\hline & Actividad sexual a temprana edad & 5 & $13,5 \%$ & \\
\hline & Edad & 0 & $0 \%$ & \\
\hline
\end{tabular}

Fuente: Mujeres de la Parroquia Colorado del cantón Montecristi

\section{Análisis:}

De las 37 encuestadas el 43,2\% iniciaron su vida sexual entre los 15 - 20 años, edades que se consideran factores de riesgo para el contagio de $\mathrm{VPH}$, se puede evidenciar que el 32,4\% han tenido entre tres o más parejas sexuales y el $37,8 \%$ solo ha tenido una pareja sexual, conociendo ellas al riesgo que se exponen, según datos proporcionados por la profesional de salud que fue parte del estudio, en el mes de enero del 2021 ya existen 5 casos de ITS, por lo que se evidencia en la tabla que el $89,2 \%$ han padecido alguna infección de transmisión sexual, podemos verificar en la tabla $\mathrm{N}^{\circ} 5$ que esto se debe a que la mayoría no utilizan preservativos como medida de prevención, y el 54,1\% de las encuestadas conocen que el factor que predispone el contagio de VPH es la promiscuidad. Todos estos resultados coinciden con los diversos autores los cuales indican que los principales factores de riesgo son las relaciones tempranas, la promiscuidad y antecedentes de infecciones de transmisión sexual.

Tabla $\mathbf{N}^{\circ}$ 5. Medidas preventivas del VPH

\begin{tabular}{|c|c|c|c|c|}
\hline Orden & Alternativa & Frecuencia & Porcentaje & Total \\
\hline \multirow[t]{4}{*}{ Prevención del VPH } & Utilizando preservativos & 26 & $70,3 \%$ & \multirow{4}{*}{$100 \%$} \\
\hline & Evitando la promiscuidad sexual & 6 & $16,2 \%$ & \\
\hline & Realizando la toma de Papanicolau & 3 & $8,1 \%$ & \\
\hline & No sabe & 2 & $5,4 \%$ & \\
\hline \multirow{2}{*}{$\begin{array}{l}\text { Conocimiento de métodos } \\
\text { de barrera para prevenir } \\
\text { el contagio }\end{array}$} & $\mathrm{Si}$ & 30 & $81,1 \%$ & \multirow{2}{*}{$100 \%$} \\
\hline & No & 7 & $18,9 \%$ & \\
\hline \multirow{3}{*}{$\begin{array}{l}\text { Uso de métodos de } \\
\text { barrera para evitar el } \\
\text { contagio }\end{array}$} & Siempre & 10 & $27,0 \%$ & \multirow{3}{*}{$100 \%$} \\
\hline & A veces & 13 & $35,1 \%$ & \\
\hline & Nunca & 14 & $37,8 \%$ & \\
\hline \multirow{2}{*}{$\begin{array}{l}\text { Conoce sobre la vacuna } \\
\text { del VPH }\end{array}$} & $\mathrm{Si}$ & 20 & $54,1 \%$ & \multirow{2}{*}{$100 \%$} \\
\hline & No & 17 & $45,9 \%$ & \\
\hline \multirow{2}{*}{$\begin{array}{l}\text { Conoce la edad de } \\
\text { aplicación de la vacuna }\end{array}$} & $\mathrm{Si}$ & 21 & $56,8 \%$ & \multirow{2}{*}{$100 \%$} \\
\hline & No & 16 & $43,2 \%$ & \\
\hline
\end{tabular}

Fuente: Habitantes de la Parroquia Colorado del cantón Montecristi

Análisis: 
En la tabla $\mathrm{N}^{\circ} 5$ se evidencia que el $70,3 \%$ de las encuestadas tienen conocimiento que el uso del preservativo previene el contagio. La pregunta 18 y 19 la relacionamos con la tabla $\mathrm{N}^{\circ} 2$ que la mayoría de las mujeres tienen conocimiento sobre el virus, sus causas y modo de transmisión, sin embargo, de las 37 encuestadas 14 mujeres nunca utilizan preservativos, 13 a veces y 10 siempre, esto muestra el desinterés por su propia salud y el riesgo al que se exponen al no utilizar preservativos. Respecto a la inmunización la Discusión

El virus del papiloma humano constituye un problema de Salud Pública, por su alta prevalencia a nivel mundial. Lo que implica una enfermedad que suele aparecer de forma asintomática por lo que puede pasar desapercibida durante mucho tiempo generando problemas de salud física, mental y social a las mujeres. De ahí el interés de los investigadores por abordar el problema de estudio. Rodríguez, Pérez y Sarduy(15) en su estudio de corte descriptivo transversal que aplicó a dos grupos de mujeres, por un lado, mujeres con diagnóstico de HPV y otro grupo que no lo posee la enfermedad, asociando los factores de riesgo con la infección. Dando lugar a una relación entre la edad de las mujeres, el inicio de la relación sexual, y la multiparidad al proceso de la infección por HPV. Por otra parte, Jorda y col., (16) en su estudio de prevalencia, a factores clínicos epidemiológicos asociados a esta infección obtiene como resultado que no hubo asociación con el embarazo, la estabilidad de la pareja, métodos anticonceptivos, edad de inicio de las relaciones sexuales ni tabaquismo, pero si fue mayor en mujeres de 15 a 24 años de edad y con más parejas sexuales. En ese sentido el estudio realizado muestra resultados similares al de otros investigadores, en donde la edad, el número de parejas sexuales, la edad del inicio de relaciones sexuales y además los antecedentes de las ITS son factores predisponentes para la preparación del HPV. Pese a ser un estudio donde se aplica una encuesta que muestra el conocimiento de las mujeres sobre la enfermedad y las formas de prevención, existe una limitación que es el cuidado propio de la salud con compromiso, pero habría que abordar en un nuevo estudio las
Vol. 4, Nro. 1, Publicado 2021-06-30

mayoría de las encuestadas conocen sobre la vacuna y la edad de aplicación. Sobre la prevención, la educación e inmunización ayudaría a disminuir el contagio. Cabe señalar que este virus se puede prevenir mediante la educación adecuada y la participación de todas las instituciones de salud, desde la niñez se deben empezar hablar sobre temas relacionados a la educación sexual para prevenir innumerables enfermedades de transmisión sexual, incluyendo el VPH y embarazos no deseados.

determinantes que hacen que las mujeres conocedoras del problema no apliquen un autocuidado para prevenir el HPV. Otras de las desventajas ante el contexto de pandemia es no poder abordar a las mujeres por medio de otra técnica de recolección de datos para profundizar el tema y darle una mayor connotación al problema.

\section{Conclusiones}

Las mujeres de esta comunidad tienen conocimiento que el virus del papiloma humano es una enfermedad de transmisión sexual, asintomática y que es el principal causante de cáncer cervicouterino en mujeres. Sin embargo, pese a que tienen conocimiento sobre la infección siguen adoptando prácticas inadecuadas para contrarrestar posibles infecciones.

Es importante hacer énfasis en la prevención a fin de reducir el riesgo de contagio de la infección. En ese sentido, tener una educación sexual adecuada, utilizar métodos de protección durante las relaciones sexuales, la inmunización y tener adecuados controles médicos ayudan a disminuir el contagio de la enfermedad. Pero la mejor manera de prevenir el contagio es la abstinencia.

La educación en salud es primordial en las diferentes poblaciones, por ello se elaboró un plan en el que se educó a los usuarios mediante vía zoom y presencial, haciendo énfasis en que la edad, la promiscuidad, la paridad, los antecedentes de infecciones de transmisión sexual, la falta o uso inadecuado de preservativos, son factores de riesgos que influyen en el contagio del virus del papiloma humano.

\section{Referencias Bibliográficas}

1. Palacios OA MSGD. Promoción de la salud sexual ante el riesgo del virus del papiloma humano. 2016;(74-88).

2. Espinoza Carrasco Freddy Andres MDGSMJA. Licenciatura de Enfermeria. [Online].; 2020. Acceso 25 de 04 de 2021. Disponible en: http://repositorio.unemi.edu.ec/handle/123456789/5196.

3. Medina ML MMML. Principales conductas de riesgo sobre Papilomavirus Humano en universitarios Argentinos. Avances En Odontoestomatología. 2018;(311-319).

4. Bustamante-Ramos GMMSATQIJC\&LMY. Conocimiento y prácticas de prevención sobre el virus del papiloma humano (VPH) en universitarios de la Sierra Sur, Oaxaca. Scielo Peru. 2015;(369-376). 
5. Jeel Junior Moya Salazar VARZ. Tendencias en la investigación del virus de papiloma humano en Latinoamérica frente a los países de altos ingresos. Revista Colombiana de Obstetricia y Ginecologia. 2017; 68(3).

6. Bohórquez PHC, Bohórquez FAB, Orellana CI. El virus del papiloma humano d ealto riesgo y su prevencion. Revista Científica Mundo de la Investigación y el Conocimiento. 2019;(1101-1117).

7. Estrada Cherres Johanna Paulina \&UCA. Diagnóstico del virus del papiloma humano en mujeres en edad fértil del área de salud No. 1 de Azogues, Ecuador. Revista informacion cientifica. 2018; 97(19-28).

8. María Emilia Acosta Merino NMEPMLVV. Virus del Papiloma Humano - Tres vacunas por una vida Campaña de concientización y prevención del VPH. [Online].; 2017. Acceso 25 de 04 de 2021. Disponible en: file:///C:/Users/admin/Downloads/131721.pdf.

9. $\quad$ Ecuador Mdspd. Plan del Switch de vacuna VPH presentación Bivalente a Cuadrivalente -2020. [Online].; 2020. Acceso 25 de 04 de 2021.

10. Diottima CCM. Repositorio UNESUM. [Online].; 2018. Acceso 25 de 04 de 2021. Disponible en: http://repositorio.unesum.edu.ec/b.

11. Contreras FASPyMNS. Repositorio Universidad de Cuenca. [Online].; 2017. Acceso 10 de 2 de 2021. Disponible

en: https://dspace.ucuenca.edu.ec/bitstream/123456789/31099/1/PROYECTO\%20DE\%20INVESTI GACI\%C3\% 93N.pdf.

12. Susana R. Domínguez Bauta TTPKAFHM. Infección por el virus del papiloma humano. revista cubana de obstetricia y ginecología. 2017; 44(1).

13. Carrión Ordóñez Julia Irma SBYPAM. Infección por virus del papiloma humano en mujeres del Cantón Cañar, Ecuador. Revista Cubana de Medicina Tropical. 2020; 72(1).

14. Pilay MEA. Repositorio UESUM. [Online].; 2018. Acceso 11 de 2 de 2021. Disponible en: http://repositorio.unesum.edu.ec/bitstream/53000/1264/1/UNESUM-ECUADOR-

ENFERMERIA-2018-05.pdf.

15. Rodríguez Dalgy, Perez Julia, Sarduy Miguel. Infección por el virus del papiloma humano en mujeres de edad mediana y factores asociados. Revista Cubana de Ginecología y Obstetricia 2014;40(2):218-232

16. Jordá Graciela, Ramos José, Mosmann Jessica, Lopez María, Wegert Adriana, Cuffini Cecilia. Prevalencia del virus papiloma humano y factores de riesgo asociados en mujeres afiliadas al seguro de salud estatal en Posadas, Misiones (Argentina). Rev. chil. infectol. 